\title{
High-speed compression molding of continuous carbon fiber-reinforced polypropylene
}

\author{
S. Enoki ${ }^{1}$, K. Kojima ${ }^{2}$, S. Mizuno ${ }^{2}$, K. Katayama ${ }^{2}$ \& K. Tanaka ${ }^{2}$ \\ ${ }^{1}$ Nara National College of Technology, Japan \\ ${ }^{2}$ Doshisha University, Japan
}

\begin{abstract}
Polypropylene (PP) is a typical thermoplastic and a superior material due to its low specific gravity, good moldability and low impact on the environment; therefore the rate by which PP is being used has increased remarkably and it is expected to be used as a matrix of carbon fiber-reinforced plastic (CFRP). However, since PP has poor interfacial adhesion to carbon fiber (CF), improvement of interfacial properties is necessary. In this study, maleic anhydride-modified polypropylene was used to improve the interfacial adhesion between carbon fiber and matrix resin. Continuous carbon fiber-reinforced polypropylene was fabricated by the high-speed compression molding method and the effect of maleic anhydride-modified polypropylene on the mechanical properties of CFRP was examined. As a consequence, the mechanical properties of CF/PP were improved by supplying $12.5 \mathrm{wt} \%$ of maleic anhydride modified $\mathrm{PP}$ to PP.

Keywords: carbon fiber, polypropylene, maleic anhydride.
\end{abstract}

\section{Introduction}

Carbon fiber-reinforced plastics (CFRPs) are expected to be used for manufacturing car component parts because of their superior mechanical properties and light weight. Automotive structures are expected to become lighter by using CFRP. In addition, considering process time and recyclability, thermoplastic resins are desirable for use as matrices. As polypropylene (PP) is a typical thermoplastic and a superior material due to its low specific gravity, good moldability and low impact on the environment, the proportion of total volume of materials for automobiles occupied by PP has reached about $20 \%$ after 
2000 [1]. However, since PP does not have a polar group and its adhesion to the reinforcing fiber is poor, it has not yet been able to take full advantage of the strength of the reinforcing fibers [2]. As a method for increasing the interfacial adhesion of CF/PP, maleic anhydride-modified polypropylene (m-PP) having polar groups such as unsaturated carboxylic acid was added to PP [3]. It is reported in past studies that the strength of the molded specimens increased, with increased interfacial strength between fibers and matrix resins $[4,5]$, when PP becomes a material with polarities after m-PP is added to it [6]. However, in molding of the continuous carbon fiber-reinforced polypropylene, the influence of $\mathrm{m}-\mathrm{PP}$ on its mechanical properties has not been discussed. In this study, continuous carbon fiber-reinforced polypropylene was fabricated by the highspeed compression molding method and the effect of the presence of maleic anhydride-modified polypropylene on the mechanical properties of CFRP was examined.

\section{Materials and experimental procedures}

\subsection{Material}

Polypropylene (PP, SA08, Japan Polypropylene Corporation) and maleic anhydride-modified polypropylene (m-PP, Yumex, Sanyo Chemical Industries, Ltd.) were used as matrix materials. They were processed into non-woven fabrics (Kuraray Co, Ltd.) by the melt blown method with a weight per unit area of $50 \mathrm{~g} / \mathrm{m}^{2}$ and $9.4 \mathrm{~g} / \mathrm{m}^{2}$, respectively. As reinforcing fabrics, non-crimp stitched carbon fabric $\left(\mathrm{NCF}, 300 \mathrm{~g} / \mathrm{m}^{2}\left[0^{\circ} / 90^{\circ}\right]\right.$ ) and PAN-based carbon fibers stitched together by polyester sewing thread, were used.

\subsection{Molding method}

Specimens were molded by the high-speed compression molding method [7]. Table 1 shows the melt flow rate (MFR) of PP and m-PP [8]. Table 2 shows the molding conditions: the molding temperature was set at $200^{\circ} \mathrm{C}$ and the molding pressure at $2 \mathrm{MPa}$. CF/PP-0, CF/PP-12.5, CF/PP-25 and CF/PP-100 represent the

Table 1: $\quad$ Melt flow rate of PP and M-PP [8].

\begin{tabular}{|c|c|c|}
\hline \multirow{2}{*}{ Temperature $\left({ }^{\circ} \mathrm{C}\right)$} & \multicolumn{2}{|c|}{ MFR (g/10 min) } \\
\cline { 2 - 3 } & Polypropylene (PP) & $\begin{array}{c}\text { maleic anhydride-modified } \\
\text { Polypropylene (m-PP) }\end{array}$ \\
\hline 160 & $<0.1$ & 48.4 \\
\hline 180 & 18.9 & $>100$ \\
\hline 200 & 25.1 & \\
\hline 220 & 58.1 & \\
\hline
\end{tabular}


cases in which the content rate of $\mathrm{m}-\mathrm{PP}$ is $0 \%, 12.5 \%, 25 \%$ and $100 \%$, respectively. As for the molding of composite laminates, NCF and resin nonwoven fabrics were laminated so that the fiber volume fraction was $50 \%$ and the thickness of the specimens was $2 \mathrm{~mm}$. The temperature history during the molding process is shown in fig. 1 . The holding time for the maximum $200^{\circ} \mathrm{C}$ temperature of the mold surface was set at $90 \mathrm{~s}$. It took only about $50 \mathrm{~s}$ to heat up the specimen from $50^{\circ} \mathrm{C}$ to $200^{\circ} \mathrm{C}$; the cooling process from $200^{\circ} \mathrm{C}$ to $50^{\circ} \mathrm{C}$ required only about $130 \mathrm{~s}$. As a whole, the molding was completed in $270 \mathrm{~s}$.

Table 2: $\quad$ Molding conditions of CF/PP.

\begin{tabular}{|c|c|c|c|c|c|}
\hline Specimen & $\begin{array}{c}\text { Content } \\
\text { rate of } \\
\mathrm{m}-\mathrm{PP}\end{array}$ & $\begin{array}{l}\text { Temperature } \\
\left({ }^{\circ} \mathrm{C}\right)\end{array}$ & $\begin{array}{c}\text { Pressure } \\
\text { (MPa) }\end{array}$ & $\begin{array}{l}\text { Holding time at } \\
\text { maximum } \\
\text { temperature } \\
\text { (s) }\end{array}$ & $\begin{array}{l}\text { Stacking } \\
\text { sequence }\end{array}$ \\
\hline $\mathrm{CF} / \mathrm{PP}-0$ & 0 & \multirow{4}{*}{200} & \multirow{4}{*}{2} & \multirow{4}{*}{90} & \multirow{4}{*}{$\begin{array}{c}\mathrm{NCF}\left(0^{\circ} / 90^{\circ}\right)_{3 \mathrm{~s}} \\
\quad\left(300 \mathrm{~g} / \mathrm{m}^{2}\right)\end{array}$} \\
\hline CF/PP-12.5 & 12.5 & & & & \\
\hline $\mathrm{CF} / \mathrm{PP}-25$ & 25 & & & & \\
\hline CF/PP-100 & 100 & & & & \\
\hline
\end{tabular}

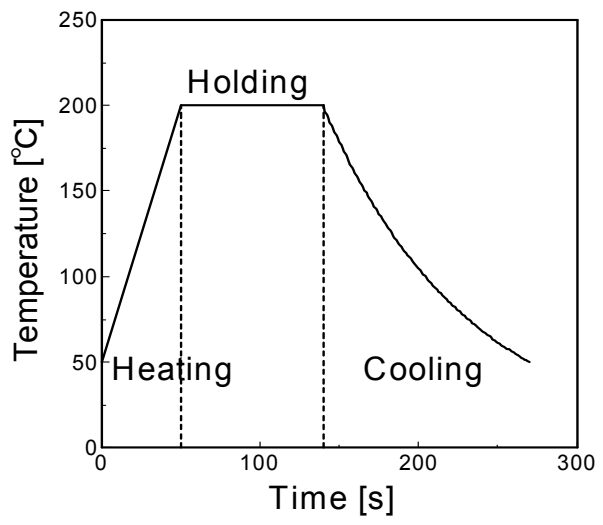

Figure 1: Temperature history of mold surface.

\subsection{Tensile tests}

Tensile tests were conducted using a universal testing machine (Autograph AG$100 \mathrm{kN}$, Shimadzu Corporation) based on JIS-K7164 and the displacement rate was set at $1 \mathrm{~mm} / \mathrm{min}$. Aluminium tabs were glued to both ends of the specimens in order to diffuse stress concentrations and their gauge lengths were $70 \mathrm{~mm}$, their width $10 \mathrm{~mm}$ and their thickness $2 \mathrm{~mm}$. Extensions between the marked 
points of the specimens were measured by video-type non-contact extensometer (DVE-201, Shimadzu Corporation).

\section{Results and discussion}

The tensile strength and elastic modulus of CF/PP obtained by the tensile tests are shown in figs 2 and 3. CF/PP-12.5 has the highest tensile strength. This shows a limit to the reinforcing effect on the interface adhesive property caused by $\mathrm{m}-\mathrm{PP}$. This is because even if $\mathrm{m}-\mathrm{PP}$ is added over a certain amount, the component of low molecular weight is increased in the matrix and the tensile strength is decreased [9]. On the other hand, CF/PP-100 has the highest tensile modulus. As shown in table 1, MFR for maleic anhydride-modified PP is

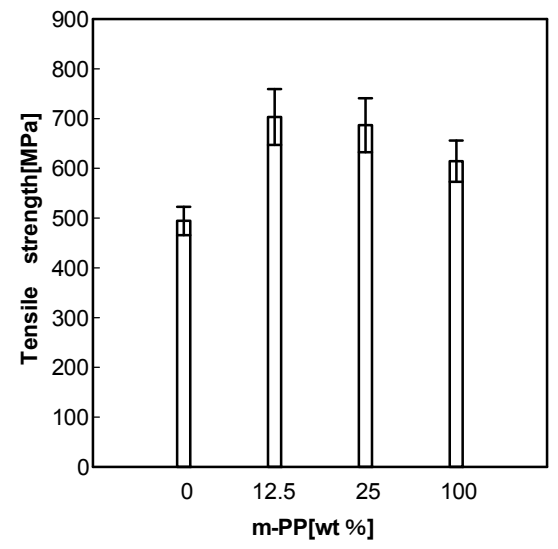

Figure 2: $\quad$ Tensile strength of CF/PP.

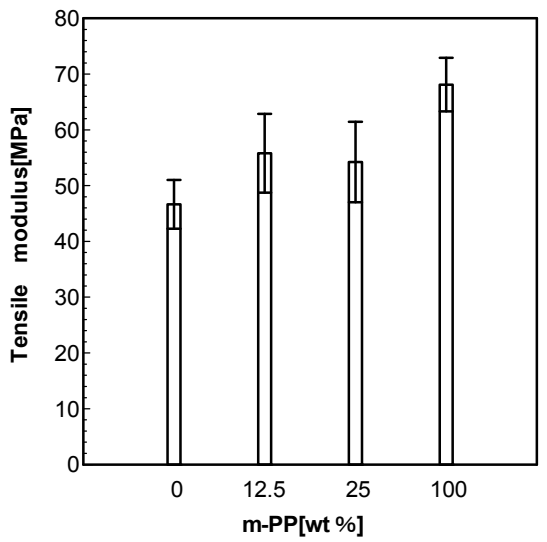

Figure 3: Tensile modulus of CF/PP. 
extremely high compared to PP. Due to the flow out of the resin during the molding process, the actual fiber volume fraction $V_{f}$ could be higher than the desired $V_{f}$ resulting in the specimen showing a higher tensile modulus.

\section{Conclusion}

Continuous carbon fiber-reinforced polypropylene was fabricated by the highspeed compression molding method and the effect of maleic anhydride-modified polypropylene on the mechanical properties of CFRP was examined. The mechanical properties of CF/PP were improved by supplying $12.5 \mathrm{wt} \%$ of maleic anhydride-modified PP to PP.

\section{References}

[1] Fujita, Y. et al., Development of polypropylene and its application to automotive parts. Car Technology, 63, pp. 16-21, 2009.

[2] Thomason, J.L. \& Yang, L., Temperature dependence of the interfacial shear strength in glass-fibre polypropylene composites. Composites Science and Technology, 71(13), pp. 1600-1605, 2011.

[3] Tamura, M., Takahashi, A., Osawa, I., Kanai, M., Uzawa, K. \& Masao, T., The interface modification effect on the carbon fiber reinforced polypropylene. 48th FRP CON-EX, pp. 111-113, 2003.

[4] Gamstedt, E.K., Berglund, L.A. \& Peijs, T., Fatigue mechanisms in unidirectional glass-fibre-reinforced polypropylene. Composites Science and Technology, 59(5), pp. 759-768, 1999.

[5] Karsli N.G. \& Aytac, A., Effects of maleated polypropylene on the morphology, thermal and mechanical properties of short carbon fiber reinforced polypropylene composites. Materials and Design, 32, pp. 40694073, 2011.

[6] Lin, C.-W., Modification of polypropylene by peroxide-catalysed grafting of maleic anhydride for adhesive bonding: surface and interface. Journal of Materials Science Letters, 12(8), pp. 612-614, 1993.

[7] Tanaka, K., Katayama, T. \& Uno, K., Eco-efficient manufacturing process of fibre reinforced thermoplastic. WIT Transactions on the Built Environment, vol. 97, eds. W.P. De Wilde \& C.A. Brebbia, pp. 203-210, 2008.

[8] Tanaka, K., Endo, N., Uemura, T. Katayama, T. \& Uno, K., Mechanical property of glass continuous fiber reinforced thermoplastics. Proc. of the 7th Asian-Australasian Conference on Composite Materials, pp. 505-508, 2010.

[9] Kumar, K.S., Ghosh, A.K. \& Bhatnagar, N., Mechanical properties of injection molded long fiber polypropylene composites, part 1: tensile and flexural properties. Polymer Composites, 28(2), pp. 259-266, 2007. 